\title{
NOTAS
}

\section{Qué y Qué No del Lunario Sentimental}

En 1910 Amado Nervo terminaba su elogio de Las montañas del oro con una exaltación de la personalidad poética: la de Lugones era " quizá la más poderosa de nuestra América".' Y eso significaba: "la inspiración más activa y consciente, el estilo más personal, el sabor lírico más intenso, el espíritu más lúcido e imperioso del Nuevo Continente latino", 2

La crítica posterior no dejó de reconocer el lugar de avanzada en que supo mantenerse el poeta argentino; reconocimiento mucho más elocuente y constante en México, donde Lugones tuvo admiradores tan ilustres como Enrique González Martínez, José Juan Tablada, Alfonso Reyes, Xavier Villaurrutia, Carlos Pellicer y Octavio Paz, además de seguidores, en modos poéticos, de la categoría de Ramón López Velarde y otros menos notables. Ya en 1899 Rafael López, en un soneto publicado en la Revista Moderna ${ }^{3}$ reconocía: Las montañas del oro "señala el camino a las líricas tropas de América"'. Más tarde, López Velarde destaca, con oportunidad, que en Lugones "el sistema poético hase convertido en sistema crítico' " $4 \mathrm{Y}$ Villaurrutia no titubea en considerarlo "el primer poeta moderno" que "inaugura en la poesía de lengua española no sólo esa irónica adoración a la luna sino también esa mezcla especiosa y rara de lo poético y lo prosaico en expresión de puro lirismo pero también de realista y descarnado acento coloquial" ' 5

En las afirmaciones de López Velarde y Villaurrutia parecen tomar pie los desarrollos y juicios igualmente afirmativos de Octavio $\mathrm{Paz}$, amigo y admirador de dichos poetas. En $E l$. arco y la lira dice Paz:

El "modernismo" también abre la via de la interpretación entre prosa y verso, lenguaje hablado y, asimismo, el vocablo técnico y el de la ciencia, la expresión en

1 Amado Nervo, Obras completas (Madrid: Aguilar, 1972), p. 391.

2 Ibid, p. 392.

3 Revista Moderna de México, II, No. 6, p. 180.

4 El don de febrero..., ed. de 1952, p. 270.

5 En Laurel, Antología de la poesia moderna en lengua espatiola (México: Editorial Séneca, 1941), p. 21. 
francés o en inglés y, en fin, todo lo que constituye el habla urbana. Aparecen el humor, el monólogo, la conversación, el "collage" verbal. Como siempre, Darío es el primero. El verdadero maestro, sin embargo, es Leopoldo Lugones, uno de los más grandes poetas de nuestra lengua (o quizá habría que decir: uno de nuestros más grandes escritores). ${ }^{6}$

Y en "El caracol y la sirena" reitera y completa su juicio:

Después de Prosas profanas los caminos se cierran: hay que replegar las velas o saltar hacia lo desconocido. Rubén Dario escogió lo primero y pobló las tierras descubiertas; Leopoldo Lugones se arriesgó a lo segundo. Cantos de vida y esperanza (1905) y Lunario sentimental (1909) son las dos obras capitales del segundo modernismo y de ellas parten, directa o indirectamente, todas las experiencias y tentativas de la poesía moderna en lengua castellana. ${ }^{7}$

Esto último es, sin duda, lo que más interesa destacar, y, sobre todo, demostrar, de la importancia (y de la vigencia, si es que la tiene hoy), del Lunario sentimental; sobre todo, después de que Pablo Neruda escribiera a Héctor Eandi, en carta de 1928, la siguiente contradictoria apreciación:

El Lugones tan denigrado, me parece en verdad rico en dotes, su poesía me parece casi siempre poética, es decir legítima, aunque anacrónica. ${ }^{8}$

Neruda, si nos atenemos a lo que opinaba de Borges, está claro que se proponía defender a quien por esas calendas era el blanco de ataques e irrespetuosidades de los martinfierristas, quienes se arrogaban todas las aventuras (pero no las desventuras) de la nueva poesía."

Muerto Leopoldo Lugones en 1938, de México llega otra vez la voz de campana glorificadora. Y es nada menos que Alfonso Reyes, quien en El Nacional de la capital azteca lanza esta advertencia consagratoria :

[Lugones] deja en el Lunario sentimentalel semillero de la nueva poesía argentina, donde no queda un palmo virgen... ${ }^{9}$

La revista Nosotros recogió el texto en el número dedicado al poeta suicida, y es el mismo Borges que antes lo habia negado, quien ahora va a escribir las palabras reivindicadoras que la Argentina le debía a su mayor poeta:

Decir que ha muerto el primer escritor de nuestra república, decir que ha muerto el 95.

6 Octavio Paz, El arco y la lira (México: Fondo de Cultura Económica, 1a. edición 1956; 2a. edición 1967), p.

${ }^{7}$ Recogido en Cuadrivio (México: Joaquin Mortiz, 1965), p. 36.

${ }^{8}$ Pablo Neruda, carta a Héctor Eandi, 24 de octubre de 1928, en Margarita Aguirre, Genio y figura de Pablo Neruda (Buenos Aires: Eudeba, 1964), p. 114.

${ }^{9}$ El Nacional (México), 27 de febrero de 1938. Recogido en Alfonso Reyes, Obras completas (México: Fondo de Cultura Económica), t. XII (1960), pp. 269-270. 
primer escritor de nuestro idioma, es decir la estricta verdad y es decir muy poco. ${ }^{10}$

Borges afirma entonces, no sólo que "Lugones fue y sigue siendo el máximo escritor argentino", sino también que el Lunario sentimental "es el inconfesado arquetipo de toda la poesía profesionalmente 'nueva' del continente'. ${ }^{11} \mathrm{Y}$ esta afirmación es reiterada por Borges con la insistencia de quien desea ser perdonado por algún error cometido a sabiendas, hasta que en 1941 publica con Silvina Ocampo y Adolfo Bioy Casares una discutida Antología poética argentina, en cuyo prólogo leemos:

...el múltiple Lugones, cuya obra prefigura casi todo el proceso ulterior, desde las inconexas metáforas del ultraismo, que durante quince años se consagró a reconstruir los borradores del Lunario sentimental. ${ }^{12}$

Bien. ¿En qué consiste esa prefiguración y qué es lo que constituye la evidencia positiva del Lunario y qué no?

Ante todo fue un libro que contiene lo más de eso que hemos visto que le asignan los mexicanos y el propio Borges. O sea: ruptura (por afirmación y negación) de ciertos tópicos del modernismo, sobre todo en lo que se refiere a la actitud vital, concepción del mundo y visión poética, que incluye un intento muy eficaz de minar la forma bella con prosaismos de toda índole y negaciones a categorías y mitos sobre los que por entonces se asentaba la validez del arte y el goce de lo bello.

Aparte de los elementos formales que marcan la novedad de este libro y que pasan a integrar el repertorio expresivo de la vanguardia, tales como la imagen libre, la ruptura del verso isócrono, la negación de la realidad como principio mimético (esto es: la poesía es una transfiguración, no es una imitación de la realidad), el Lunario sentimental presenta una concepción del hombre y del mundo como duda de la verdad del ser y de la realidad de las cosas: es decir, como derrumbe de lo establecido, especie de picapedrero que va a explotar, por un lado, con la visión poética del ultraísmo y del creacionismo, y por otro, como búsqueda de una nueva verdad humana y artística, con el surrealismo. La ironía, que es lo más obvio y hasta patético de esta obrita tan antipoética, se esgrime como respuesta o contraataque a la tentación de la nada, y, sobre todo, como esguince para salvar el abismo entre lo real y lo imaginario. El vocabulario cientifico y el enfrentamiento de lo doméstico a lo cósmico son novedades que no podrán soslayar las vanguardias más al día o hasta ahora el más dramático e indescifrado de nuestros poetas, César Vallejo.

Todo esto constituye tanto el qué como el qué no de Lugones, su anacronismo, como opina Neruda, o su permanente actualidad, como sostiene Borges, por lo menos cuando dice: "el genio de Lugones es magnificamente verbal" ${ }_{13}^{13}$ Borges reconoce:

${ }^{10}$ Nosotros, 1938. Recogido en Leopoldo Lugones (Buenos Aires: Ediciones Troquel, 1955), p. 81. Véase también p. 78, donde hay un adelanto de ese juicio.

11 Leopoldo Lugones, pp. 83 y 85.

12 Publicado por la Editorial Sudamericana de Buenos Aires, 1941. La cita es de la página 8.

${ }^{13}$ Leopoldo Lugones, p. 9. 
La literatura de América aún se nutre de la obra de este gran escritor; escribir bien es, para muchos, escribir a la manera de Lugones. Desde el ultraísmo hasta nuestro tiempo, su influjo perdura creciendo y transformándose. Tan general es ese influjo que para ser discípulo de Lugones, no es necesario haberlo leído. ${ }^{14}$

Desde luego ésta podría ser una exageración muy borgiana; pero en el fondo hay una verdad indiscutible: Lugones introdujo en América un nuevo sentido de la profesionalidad artística, que no es sólo el "persigo una forma" de Dario, sino la convicción de que toda poesía es una virtualidad lingüística. Y que esa naturaleza lingüística de la literatura es una toma de conciencia (como en Baudelaire y Mallarmé) de que por el lenguaje la poesía se establece a sí misma como posibilidad crítica. La realidad es una inmanencia de la palabra poética; es decir : toda la realidad es poetizable porque el póeta tiene el don de realizarla por virtud de su voluntad de arte. En poesía, el arte está en la capacidad de posesión y transformación de la realidad por medio del lenguaje que niega significados, relaciones, sentidos y los da en un organismo único de relaciones, significados y sentidos intransferibles. Así, el arte (en su sentido latino de ars) es la máscara de la naturaleza y de la vida, transferencia, figura de la realidad. Persona, diría Ezra Pound.

Desde Góngora (con quien Lugones tiene en común, además de la negación de las relaciones naturales del signo lingüístico con la realidad mentada, la propensión a diluir lo referencial, o, por lo menos, a reducirlo al unitema como en las Soledades), ningún poeta de nuestra lengua había llevado tan lejos la libertad combinatoria de una poiesis sometida a la tekne. Y no cabe duda de que este arte combinatorio es lo más característico del hacer (o componer) lugoniano, sus procedimientos barroquizantes más obvios: la artificialización y la parodia. Tentado estoy de asimilar este proceso de desrealización acumulativa a lo que Mikhail Bakhtine (y siguiendo a él Severo Sarduy) ha llamado la carnavalización de la literatura. Cantar a la luna con todas las fuerzas del arte, para "burlarse de la vida", parece ser menos la proclamación jubilosa del goce lúdico que superar, como nuestro autor se proponia, "el hastio de las cosas iguales", O puede ser arrogancia que se perpetra con los poderes de la mente. De ahí su esguince irónico (no importa ahora si lo tomó de Laforgue), ese sonambulismo selénico cuya base está en presentar una realidad fingidacomo verdadera, pero con la seguridad de que se está haciendo lo contrario de lo que se es. En suma: una "Plegaria de carnaval", título de un poema que parece ser el comentario de su génesis o método creador:
$\mathrm{Y}$ toda esta alta fama con que elogiando vengo
tu faz sietemesina de bebé en alcohol,
los siglos te la cuentan como ilustre abolengo, porque tú eres, oh luna, la máscara del sol.

La luna es "máscara del sol" ; el arte ¿será acaso la máscara de la vida? En fin: no quiero abusar de las interpretaciones. Además, me parece que la ironía no es un fin, sino un medio, parte, fundamental sin duda, del método por el cual se resuelve la escritura

${ }^{14}$ Op. cit., p. 10 . 
lugoniana. La otra parte la constituye el uso pleno de la imaginación, que Lugones distingue de la fantasía al modo romántico, para ejercer el dominio supremo en la ejecución de la palabra poética. Porque para este Lugones del Lunario toda palabra es ahora vehículo de una realidad única e independiente de la ideación, la formulación del concepto, la notación sensorial o la significación emotiva. Actitud deshumanizante por la cual las palabras viven solas como en un juego de cartas o un rompecabezas, nunca resuelto. El poeta se niega como vigía de sí mismo para que la palabra asuma la responsabilidad plena de su vigilancia más desvelada. ¿Creacionismo total por medio del lenguaje en función absoluta? ¿Ultraísmo puro cuando todavía no se había inventado la palabra?

Para Lugones la palabra y la imaginación son los dos elementos activos del fenómeno poético ${ }^{15}$;por losicuales:toda la realidad puede ser cambiada, transformada, re-creada. Dice Lugones:

[|...]: la civilización no es otra cosa que el conjunto de ciertas invenciones, comunicaciones y convenios cuya expresión irreemplazable es la palabra. Falte la palabra, y todo aquello ya no existe. El hombre ha desaparecido como ser social. Por esto la palabra es el destintivo de su superioridad entre los seres. ${ }^{16}$

Esta concepción de la palabra nos lleva al centro mismo de la poética lugoniana como abertura a la poética vanguardista y de post-vanguardia: es su teoría de la imagen como principio creador de un espacio poético. Lo que menos nos interesa hoy del prólogo al Lunario sentimental es su predilección por la rima y el verso libre. Tampoco nos atraen sus enumeraciones caóticas, sus inclusiones de lo anti-poético, lo no lírico (lo feo), el lenguaje científico y la anti-personalización como resultado de la devaluación del hombre y del mundo, sometidos a la técnica, a la mecanización. Las adjetivaciones raras y forzadas, la sustantivación grotesca o caricaturesca, el verbo en continua transgresión de las funciones normales son procedimientos que hoy dejan ver demasiado la voluntad activa (de retórica actuante y hasta polémica) del estilo lugoniano. Pero Lugones también abrió el camino al diálogo con el lector, mediante lo coloquial cotidiano: una especie de entendimiento entre lo vulgar y lo burgués:es la estética von unten y la von oben (lo de abajo y lo de arriba), como quería Fechner.

Como acierta a decir Ezequiel Martínez Estrada:

Lugones no siente directamente las cosas, sino a través de su mundo artístico. Pero las fuerzas impetuosas llegan a él desde las cosas mismas. ${ }^{17}$

Esas "fuerzas impetuosas" actúan para enfrentar lo racional y sistemático al asedio de lo misterioso: razón frente a fe, que es como decir lo hecho (lo dado) frente a lo que debe

\footnotetext{
15 : Ver esto en Alfredo Roggiano, Situación y tendencias de la nueva poesia argentina (Washington: Pan American Union, 1963), pp. 8-14.

16 Leopoldo Lugones, "Rubén Darío"' [conferencia pronunciada en 1916] cfr. Roggiano, op. cit., p. 9. 127.

17 Ezequiel Martínez Estrada, Leopoldo Lugones, retrato sin retocar (Buenos Aires: Emecé Editores, 1968), p.
} 
hacerse (o debe ser). Lugones asume el sentido dramático de la inutilidad de la vida, del ser, sin su capacidad de reducirlo a la nada y de reconducirló desde el no-ser a la certeza poética y metafísica. De ahí su refugio en lo grotesco, la burla, la caricatura, que es dualidad formada por la realidad y un reflejo ideal que la remeda, y así la hace posible en la creación. Como puntualiza Sola González:

doble visión del estrabismo realista-idealista convergente en los resultados de la irŏnía. ${ }^{18}$

Ya en 1910 el maestro Pedro Henríquez Ureña proponía:

Si a alguien pudiera dársele el título de Góngora americano (título de nobleza no corrompida pero sí peligrosa por su osadía), a Leopoldo Lủgones le correspondería en todo caso: él es quien ha polularizado entre nosotros un estilo imaginativo singular cuyo más notorio recurso es la trasmutación de lo objetivo en sưbjetivo y viceversa. ${ }^{19}$

Desde luego éste es un procedimiento que no inventó Lugones, pero está en la base de una de las más efectivas renovaciones de la escritura poética: el barroco, cuyo principio creativo radica en la ruptura del orden analógico, en el juego libre de la imaginación, a la que-según palabras de nuestro poeta-hay que dejarla " andar como quien divaga por un vergel sin caminos". 20 !

Con este sentido del divagar de la imaginación Lugones entra de lleno en la ambigliedad poética, la pluralidad semántica y la diversidad asociativa. Devolver a las palabras su aureola imaginativa, como diria Bachelard, y dar a la metáfora el poder de revelar la analogía de lo disímil, fue uno de los objetivos fundamentales de la voluntad renovadora de Lugones, quien había visto en París, antes de 1910, los experimentos artísticos y literarios del cubismo, el futurismo y Apollinaire. El Lunario sentimental sería, pues, un libro experimental, el más avanzado y atrevido hasta entonces en lengua española (antes de Gómez de la Serna, quien empieza a publicar greguerías en 1910). Lugones se constituye, así, en atalaya y vigía de lo que Octavio Paz llamará más tarde "la tradición de la ruptura". Ruptura que deshace y re-ordena con una liberación, que es limpieza del tedio o la desidia del lenguaje y su relación con la realidad (contra el desarrollo elocutivo, "representativo", del discurso y contra el análisis sentimental del poema), como lo propondría después la vanguardia. Agregación de un espacio como distancia poética entre los términos más disímiles que van a sostener la realidad como virtualidad discontinua del poema. Ni elocuencia, ni oratoria; ni descriptivismo ni asunción explicativa, sino la deformación como proceso formante y sugerente: multiplicidad de apariencias en la inconstancia de signos y significados; esto es: la poesía-otra, el poeta-persona, la certeza de la máscara.

\footnotetext{
${ }^{18}$ En Revista Iberoamericana, No. 61, p. 24.

${ }^{19}$ Pedro Henriquez Ureña, Horas de estudio (Paris: Ollendorf, S.A., 1910), p. 116. Nota al artículo titulado "Rubén Dario".

${ }^{20}$ Artículo sobre Dario, citado, p. 10.
} 
He ahi el qué del Lunario sentimental. Olvidar todo lo demás es asegurar la inoperancia de un qué no ya redimido.

University of Pittsburgh

ALFREDO A. ROGGIANO 
